\title{
A Morfologia e o Papel dos Vazios Urbanos na Região Metropolitana de Vitória-ES
}

\author{
The Morphology and the Role Urban Voids in Region Metropolitan of Vitoria-ES
}

La Morfologia y el Papel dos Vacíos Urbano la Región Metropolitana de Vitória-ES

\author{
Francismar Cunha Ferreira ${ }^{1}$ \\ Cláudio Luiz Zanotelli ${ }^{2}$
}

Recebido em 23/09/2016. Aceito em 11/04/2017.

\begin{abstract}
RESUMO: O artigo analisa os vazios urbanos da Região Metropolitana de Vitória (RMGV). Mapeia a morfologia de vazios urbanos e as relações que eles têm com a renda da terra e a expansão do espaço urbano. Foi constatado que a área urbana da região é mais vazia do que edificada, $71 \%$ da área urbana delimitada pelos perímetros urbanos dos municípios que compõem a região é constituída desses vazios. Revelando que os proprietários fundiários têm um papel de primeiro plano na expansão do aglomerado urbano.
\end{abstract}

Palavras - Chaves: Vazio urbano; Renda da terra; Espaço urbano.

ABSTRACT: The article analyzes the voids urban Metropolitan Region of the Vitória-ES. It was mapping the morphology of urban's voids and the relation they have with the rent of land and the expansion of urban space. It has been found that the urban area of the region is more "voids" than built, $71 \%$ of the urban area bounded by the urban perimeter of the cities that make up the region consists of these voids. Revealing that the landowners have a leading role in expanding the urban area.

Keywords: Urban Voids ; Rent of land ; Urban spaces.

RESUMEN: El artículo analiza el vacíos urbanos de la Región Metropolitana de Vitória-ES. Fue mapeo la morfología de los vacíos urbanos y las relaciones que tienen con la renta de la tierra y la expansión del espacio urbano. Se ha encontrado que el área urbana de la región es más "vacío" que construyó, el $71 \%$ del área urbana delimitada por el perímetro urbano de los municipios que conforman la región se compone de estos vacíos. Revelando que los terratenientes tienen un papel destacado en la expansión de la zona urbana.

Palabras - Clave: Urban vacías; Renta de la tierra; Espacio urbano.

\section{INTRODUÇÃO}

A Região Metropolitana da Grande Vitória (RMGV) localizada no Estado do Espírito Santo é composta por sete municípios (cf. mapa 01) e possui uma área total de aproximadamente $2.311 \mathrm{~km}^{2}$ o que corresponde a pouco mais de $5 \%$ do território estadual. Além disso, Possui uma área urbana de aproximadamente $846,45 \mathrm{~km}^{2}$ (cf. quadro 1). Quanto aos aspectos econômicos, o Produto Interno Bruto (PIB) da RMGV corresponde a 
63,15\% do PIB do Estado (ZANOTELLI et. al, 2014). Em seus aspectos populacionais, de acordo com o Instituto Brasileiro de Geografia e Estatística (IBGE, 2010), a RMGV possui uma população de 1.687 .704 habitantes, o que representa $48 \%$ da população do Espírito Santo. Sua densidade demográfica é de aproximadamente 730 habitantes por quilômetro quadrado.

A RMGV sofreu significativas transformações (urbanas, sociais, ambientais, etc.) principalmente, a partir da década de 1960, em função da implementação de grandes projetos industriais como a instalação da Companhia Vale do Rio Doce (CVRD atual Vale), da Companhia Siderúrgica de Tubarão (CST atual Arcelor Mittal) da implantação do Centro Industrial da Grande Vitória I e II (CIVIT I e II) e das empresas localizadas em sua área de influência: Aracruz Celulose (hoje Fibria) e a Samarco. A implementação desses e de outros projetos industriais, somada à política federal de erradicação dos cafezais, fez com que se alterassem as bases produtivas do estado - de predominantemente agrícola para uma indústria de transformação de produtos primários - e que consequentemente, a RMGV recebesse um significativo contingente de migrantes, vindos do interior do Espírito Santo e de outros estados, em função de sua importância como local sede de indústrias e centro comercial e político, o que culminou no aumento da população, principalmente urbana, e promoveu uma expansão da mancha urbana da região.

Em função do rápido crescimento urbano, associado a vários outros aspectos históricos, a região veio consolidar um espaço urbano relativamente disperso, com a presença de vazios urbanos que são, de maneira geral, espaços não edificados. São vazios no sentido formal, pois não são construídos, mas ao mesmo tempo, são plenos de significados, uma vez que esses vazios se encontram controlados por proprietários de terra que desenvolvem sobre e nesses espaços diversas estratégias de apropriação da renda da terra. Nesse sentido, os vazios urbanos (representados por lotes, glebas e até mesmo fazendas que se encontram no interior da área urbana), podem ser reserva de terras para ganhos dos proprietários fundiários que buscam desenvolver diversas estratégias para a apropriação da maior renda da terra possível. Entendemos os vazios como processos socioeconômicos e espaciais operativos e sua cristalização concreta sob a forma de uso do espaço juridicamente consagrada de propriedade pública ou privada (lotes, glebas, loteamentos, fazendas etc.). Vazios em nossa concepção não tem o sentido de reiterar o significado comum que envia à noção de espaço destituído de qualquer coisa ou de pessoas ou ainda do significado que se deu durante muito tempo à ocupação do território brasileiro considerando-o como vazio de gente. Políticas e discursos que visavam e visam legitimar as incorporações de terras ao front pioneiro, à conquista do território independente de sua gente. O vazio que analisamos, na falta de palavra que conote melhor o fato a ser estudado, 
é um espaço que se insere numa trama de interesses e de luta de poder e relações de forças, faz parte do campo social sobre o qual se inscreve a sociedade, portanto, tem estrutura, função, forma e conteúdo; não é um lugar sem espaço, mas um lugar no mundo que não é, provisoriamente, ocupado por construções. Ele assim é chamado por contraste com os plenos dos espaços urbanos e revela, pela falta dessas construções e os lugares onde se inserem, intenções as mais variadas daqueles que controlam sua propriedade e a possibilidade de definir seus usos.

Quanto à renda da terra, na perspectiva marxista, pode ser entendida como uma parte do mais valia social que os proprietários de terra drenam para seus bolsos em função do controle jurídico que detém sobre porções de terra (MARX, 1988). A renda seria, de maneira geral, uma espécie de "pedágio" manifestado pelo preço de venda ou de locação da propriedade da terra que o proprietário cobra para disponibilizar a propriedade da terra para outros agentes $^{3}$ (SEABRA, 1979).

Nesse contexto, o presente artigo tem como objetivo, estudar os vazios urbanos e suas implicações na expansão da área urbana da RMGV. Tendo isso em vista, nos colocamos os seguintes questionamentos: Quais as relações e implicações dos vazios urbanos com a cidade, em especial com a expansão da mancha urbana e dos perímetros urbanos da RMGV? Onde se localizam e qual a dimensão desses espaços na RMGV? Quais são suas características?

Para respondermos a essas questões e atingir nossos objetivos realizamos um mapeamento da morfologia dos vazios urbanos da RMGV basicamente de duas maneiras. Em uma primeira, trabalhamos com os vazios urbanos que identificamos por meio da subtração entre a área urbana apontada como densa (disponibilizada em formato shapefile ${ }^{4}$ pelo Instituto Jones dos Santos Neves (IJSN, 2010)) e os limites dos perímetros urbanos (disponibilizados em formato shapefile pelo IJSN (2010)) dos municípios da RMGV. Esses vazios identificados nesse primeiro momento, de modo geral, se localizam nas franjas urbanas, fora da mancha urbana apontada como densa, mas dentro do perímetro urbano. São espaços que podem possuir algumas poucas e dispersas edificações, mas que quando analisados em escala metropolitana ou até mesmo municipal podem ser consideradas como vazios urbanos. Esses vazios foram aqui classificados como vazios periurbanos.

Em um segundo momento, realizamos um trabalho de identificação, delimitação e classificação dos vazios urbanos que se encontram no interior da área urbana apontada como densa. Essa identificação de uma morfologia foi realizado a partir de análise da ortofoto de 2007/2008 disponibilizadas pelo Instituto Estadual de Meio Ambiente (IEMA) e a partir da delimitação da mancha urbana densa de 2010, disponibilizada pelo IJSN, (2010). O mapeamento foi realizado em uma escala de análise de 1:3000 por meio do software Arcgis 
9.3, e a delimitação dos vazios se deu de modo "manual", onde vetorizamos/delimitamos "manualmente" os vazios identificados na ortofoto, uma vez que não foi possível reunir a base de lotes de todos os municípios da RMGV para identificar apenas os lotes vagos. Nessa direção, o que foi identificado e delimitado como vazios não são necessariamente apenas os lotes vagos - esses correspondem a grande maioria -, mas áreas vagas, ou seja, delimitamos áreas vagas sem seguir estritamente os limites dos lotes, logo, grandes quintais resultantes de pequenas edificações em grandes lotes, por exemplo, podem ter sido identificados como áreas vagas. Todos esses vazios foram classificados no presente trabalho como sendo vazios urbanos dentro da mancha urbana densa.

Depois de identificados e mapeados os vazios urbanos dentro da mancha urbana densa, realizamos uma classificação deles conforme suas características. Assim categorizamos os vazios urbanos dentro da mancha urbana densa em: vazios com elevado potencial de edificação, áreas de interesse ambiental dentro da mancha urbana, vazios de uso coletivo e vazios complexos.

Vale ressaltar que o mapeamento aqui apresentado possui algumas limitações, basicamente, devido: a resolução espacial limitada da ortofoto que corresponde a um para um, onde cada pixel da imagem corresponde a um metro do espaço real; aos aspectos físicos em especial ao relevo que devido sua morfologia produz sombras em alguns pontos da ortofoto; a vegetação de alto porte arbustivo dificulta a visualização das ocupações; e, por fim, o próprio modo de ocupação, a exemplo de locais que foram ocupados de maneira "informal", onde as casas e os lotes se misturam de modo "aparentemente aleatório" dentro de uma gleba, dificultando assim a delimitação dos espaços vagos. Ainda em relação ao modo de ocupação, tem-se o problema de sombras produzido por edifícios. Entretanto, o agravante maior fica por conta de áreas que associam esses elementos limitantes. $\mathrm{Na}$ tentativa melhor mapear esses espaços, e de superar, em parte, essas barreiras, buscamos auxilio de imagens do Google Earth (2014/2015).

Vale ressaltar que além do trabalho de delimitação dos vazios urbanos em geral, realizamos ainda uma revisão da literatura acerca dos vazios urbanos a partir de trabalhos teóricos e empíricos, sobre a produção do espaço urbano e sobre a renda da terra.

\section{CONSIDERAÇÕES SOBRE OS VAZIOS URBANOS}

As questões inerentes aos vazios urbanos ganharam destaque a partir da década de 1970. Nesse período, eles deixaram de ser concebidos unicamente como sendo espaços verdes ou áreas livres, para se tornarem verdadeiros impasses para as cidades (SILVA, 1999; TEIXEIRA; FURTADO, 2010). 
De acordo com Borde (2004) vários são os termos utilizados para qualificar esses espaços, tais como, terrain vague, friches urbaines, wastelands, derocict lands, tierras vacantes e vazios urbanos. No presente trabalho, utilizaremos o termo vazio urbano.

Como vazio urbano ${ }^{5}$ compreendemos toda área parcelada ou não, localizada em meio à área qualificada como urbana delimitada pelo perímetro urbano, que não possuem edificações ou que se encontram subutilizadas. Desse modo, os vazios urbanos são áreas não edificadas, podendo ser um lote, uma área, uma fazenda, ou até mesmo, espaços não edificados de grandes lotes ocupados por pequenas construções (SPERANDELLI, 2010). Nessa direção, os vazios urbanos se apresentam nas cidades por meio de várias situações originados de diferentes maneiras, tais como, terrenos baldios, áreas remanescentes da ocupação de lotes, áreas de interesse ambiental dentro das cidades, terras sem uso definido próximo a infraestruturas industriais, ferroviárias, portuárias e etc. (CAMPOS, 2004).

De maneira geral, os vazios urbanos se configuram como sendo intervalos e lacunas em meio ao espaço construído e também como sendo espaços sem edificações adjacentes à mancha urbana densa e podem ser considerados espaços urbanos ou sob a influência da zona urbana devido à delimitação - muitas vezes estapafúrdia e sem comum medida com a verdadeira área urbana - do perímetro urbano (CAMPOS, 2004; SPERANDELLI, 2010).

Deve-se ressaltar que esses princípios que caracterizam os vazios urbanos, apenas os qualificam em seus aspectos formais, e até mesmo simbólicos, pois o espaço vazio é apresentado apenas como sendo o contrário do espaço que é ocupado, construído. Mas esses espaços também devem ser considerados como plenos, ou cheios de sentido e onde a norma jurídica assegura o ordenamento de seus possíveis usos (de interesse coletivo ou particular). Isso significa apontar que eles constituem porções do espaço urbano que são controladas por proprietários de terra (privados ou públicos). Logo, esses proprietários podem procurar rentabilizá-los ou não. Portanto, parte considerável desses espaços também pode ser analisada a partir de uma perspectiva rentista da cidade.

Muitos proprietários particulares dos vazios urbanos estão à espera de valorização desses espaços, deixando essas áreas "aparentemente fora do mercado imobiliário" esperando que a sociedade coletivamente invista uma determinada quantidade de capital para a produção de uma localização. Dessa forma, o proprietário individual se apropria de toda a localização produzida socialmente para assim ter sua terra valorizada. Nessa perspectiva os vazios urbanos se configuram como uma questão de ordem econômica.

Os vazios urbanos são uma questão de ordem social, uma vez que o acesso à propriedade terra se torna cada vez mais seletivo, em particular nos centros urbanos. Os setores sociais que compõem as categorias dos mais dominados dentre os dominados não tendo condições de pagar para desfrutar de um bem coletivo - localização com lugares com 
serviços e infraestruturas suficientes - são, em muitas ocasiões, forçados a buscar terras baratas que se localizam nas periferias longínquas. Em alguns casos, os mais pobres expropriados da terra veem como única solução a ocupação irregular, que em muitas vezes ocorrem em áreas que apresentam riscos para ocupação, como encostas instáveis, zonas inundáveis e etc.

Todavia deve-se ressaltar que esses vazios urbanos podem ser equivalentes à noção de espaços livres apontada por Tardin (2008). Para essa autora, os espaços livres seriam espaços não ocupados por construções e infraestruturas viárias, que podem vir ser articulados com a área urbana (TARDIN, 2008). Seriam espaços de qualidade ímpar que podem ter a função de proporcionar usos de importância ambiental, paisagística e recreativa dentro da cidade, e serem utilizados de maneira articulada ao urbano, às áreas mais densas.

Portanto, os espaços vazios não são vistos aqui de maneira pejorativa, ou como destituído de vida, de qualidade e importância ambiental e/ou de alguma função social. Isso, pois acreditamos que os vazios urbanos não estão necessariamente atrelados a práticas especulativas e que também esses espaços podem ser pensados de maneira articulada com o espaço urbano.

Além disso, deve-se ressaltar que nem todos aqueles vazios que apresentam condições favoráveis às edificações são utilizados especulativamente, pois se deve considerar a possibilidade da falta de recursos de alguns proprietários para se construir e ocupar um imóvel e também a possibilidade de usos alternativos nesses espaços como, por exemplo, a criação de hortas comunitárias, reservas, parques e áreas de proteção ambiental, etc.

De modo geral, diante dessas questões, pode-se considerar que

(...) esses "vazios urbanos" fazem parte de um sistema, de uma diagramática gerativa que pela "presença-ausência" política (com a definição do perímetro pelo município) e econômica (com os interesses dos proprietários fundiários) indica, em filigrana, de maneira virtual, mas atual, os possíveis usos e ocupações futuras. Identificando-se, assim, e se antecipando, um movimento de valorização por meio da tão esperada renda da terra. (...) Portanto, o vazio é aquilo por onde o plenamente ocupado pode fazer sentido, é o que dá sentido à estrutura espacial, ele manifesta aquilo que muitos atores sociais esperam da expansão da cidade: ganhos substanciais tirados do fato de possuir uma propriedade (legal ou ilegalmente). Evidentemente eles possibilitam outros usos alternativos de projetos territoriais que não se circunscrevam aos interesses especulativos, mas esse não nos parece ser o que sobredetermina relativamente em última instância o processo de ocupação das franjas da região metropolitana hoje. (ZANOTELLI et. al. p. 2, 2014a). O grifo é nosso. 
Devido a essas particularidades - principalmente pelo predominante caráter especulativo - os vazios urbanos e a capacidade de gerar renda a seus proprietários acabam se tornando uma questão central para a compreensão da organização e do uso do solo urbano, afinal, por um lado, áreas que deveriam ser preservadas em função de sua importância ambiental são pressionadas pelo mercado de terras e pelo mercado imobiliário e, por outro lado, o acesso à terra urbana e aos vazios urbanos que possuem potencial construtivo e com infraestrutura urbana, se torna algo seletivo, motivando um processo de expansão e dispersão da mancha, uma vez que os altos preços dessas áreas vagas dificultam o acesso a elas.

Essa expansão urbana que se baseia e/ou pode levar ao rentismo, que condiciona uma urbanização dispersa com a forte presença de vazios urbanos, motiva o surgimento de significativos problemas às municipalidades, pois, se torna necessário com o tempo de dotar esses lugares de equipamentos urbanos construídos ou mantidos predominantemente pelas prefeituras, sendo que ao mesmo tempo, eles podem ficar subutilizados. Em contrapartida, os proprietários dos vazios têm suas terras valorizadas por esse processo. Evidentemente há casos como dos condomínios/loteamentos fechados Alphaville onde a infraestrutura intramuros é construída pelos próprios empreendedores, no entanto, ela deve ser conectada às redes coletivas e condiciona a qualidade dessa mesma rede que em muitos casos, é estruturalmente deficiente.

Nessa direção, sendo o vazio urbano uma problemática relevante nos contextos das cidades cabe perguntar; qual a dimensão dos vazios urbanos na RMGV? Onde se localizam? Quais são seus possíveis efeitos sobre a expansão urbana da região de Vitória? Questões que buscaremos responder a seguir.

\section{A MORFOLOGIA dOS VAZIOS PERIURBANOS DA REGIÃO METROPOLITANA DE VITÓRIA}

Os vazios periurbanos conforme indicado anteriormente, foram identificados por meio da subtração entre a área urbana densa e os limites dos perímetros urbanos dos municípios da RMGV. O resultado desta análise pode ser visualizado na quadro 1 e no Mapa 1.

Analisando-os, uma das primeiras coisas que se destaca são as grandes áreas dos perímetros urbanos em contraste com manchas urbanas e, consequentemente, as grandes áreas de vazios periurbanos. No caso do município de Guarapari a relação entre perímetro urbano e mancha urbana é algo surpreendente. O município possui uma área urbana densa de aproximadamente $34 \mathrm{~km}^{2}$ e um perímetro urbano que apresenta cerca de $257,78 \mathrm{~km}^{2}$. Em função disto, Guarapari é o município com a maior área e o maior percentual de vazios periurbanos da região, com $223,78 \mathrm{~km}^{2}$, o que representa $86,8 \%$ da área delimitada como 
hipoteticamente urbana. Destacam-se ainda os casos dos municípios de Fundão, Vila Velha e Cariacica que possuem mais de $50 \%$ de suas áreas urbanas delimitadas pelos perímetros urbanos como sendo vazios periurbanos. Serra por sua vez apresenta uma área de vazios periurbanos de $91,55 \mathrm{~km}^{2}$, o que corresponde a $47,8 \%$ de sua área urbana delimitada pelo perímetro urbano. Vitória ao todo, apresenta $29,4 \mathrm{~km}^{2}$ de vazios periurbanos, esses que em grande parte correspondem, a áreas da proteção ambiental. Em síntese, a RMGV apresenta uma área de $504,52 \mathrm{~km}^{2}$ de vazios periurbanos, o que corresponde a aproximadamente $60 \%$ do espaço delimitado como perímetro urbano (ZANOTELLI et. al. 2014).

Quadro1: Características territoriais da Região Metropolitana de Vitória.

\begin{tabular}{|c|c|c|c|c|c|c|c|c|}
\hline Município & $\begin{array}{l}(\mathrm{I}) \\
\text { Área } \\
\text { total } \\
\left(\mathrm{km}^{2}\right)\end{array}$ & $\begin{array}{l}\text { (II) } \\
\text { Área } \\
\text { rural } \\
\left(\mathbf{k m}^{2}\right)\end{array}$ & $\begin{array}{c}\text { (III) } \\
\text { Área urbana } \\
\text { delimitada } \\
\text { pelo } \\
\text { perímetro } \\
\text { urbano }\left(\mathbf{k m}^{2}\right)\end{array}$ & $\begin{array}{c}(\mathrm{IV}) \\
\text { Mancha } \\
\text { urbana } \\
\text { densa } \\
\left(\mathbf{k m}^{2}\right)\end{array}$ & $\begin{array}{c}(\mathrm{V}) \\
\text { Área de } \\
\text { proteção } \\
\text { ambiental no } \\
\text { interior do } \\
\text { perímetro } \\
\text { urbano, mas } \\
\text { fora da mancha } \\
\text { urbana densa } \\
\left(\mathrm{km}^{2}\right) \\
\end{array}$ & $\begin{array}{c}(\mathrm{VI})= \\
(\text { III-IV-V) } \\
\text { Vazios } \\
\text { Periurbanos } \\
\left(\mathrm{km}^{2}\right)\end{array}$ & $\begin{array}{c}(\mathrm{VII})=(\mathrm{III}- \\
\text { IV }) \\
\text { Área Total } \\
\text { de vazios } \\
\text { periurbanos } \\
\left(\mathrm{km}^{2}\right)\end{array}$ & $\begin{array}{c}\% \text { de } \\
\text { vazios } \\
\text { periurba } \\
\text { nos }\end{array}$ \\
\hline Cariacica & 279,65 & 150,34 & 129,31 & 64 & 0 & 65,31 & 65,31 & 50,5 \\
\hline Fundão & 286,77 & 269,55 & 17,21 & 5 & 0 & 12,21 & 12,21 & 71 \\
\hline Guarapari & 589,14 & 331,36 & 257,78 & 34 & 65,31 & 158,47 & 223,78 & 86,8 \\
\hline Serra & 547,44 & 355,89 & 191,55 & $100^{*}$ & 0 & 91,55 & 91,55 & 47,8 \\
\hline Viana & 312,22 & 283,63 & 28,6 & 16 & 0 & 12,6 & 12,6 & 44 \\
\hline Vila Velha & 209,87 & 74,2 & 135,67 & 66 & 6,2 & 63,47 & 69,67 & 51,5 \\
\hline Vitória $^{\star \star}$ & 86,33 & 0 & 86,33 & 45 & 21,96 & 7,44 & 29,4 & 34 \\
\hline Total & $2.311,42$ & $1.464,97$ & 846,45 & 330 & 93,47 & 411,05 & 504,52 & 60 \\
\hline
\end{tabular}

* Inclui a área da APA de Praia Mole que se localiza dentro da mancha urbana densa.

**11,93 km² de Vitória que constam da área total no quadro correspondem à área da Baia de Vitória e as ilhas oceânicas.

Fonte: IBGE (2010), IJSN (2010) e adaptado de Zanotelli et. al. (2014).

A definição de extensos perímetros urbanos por si só já se apresenta como um fato que pode trazer impactos diversos para as municipalidades da região, afinal, empreendimentos urbanos como loteamentos e etc., pode surgir em diferentes lugares sem apresentar uma continuidade com a mancha urbana consolidada, o que pode motivar maiores custos para as municipalidades em função da infraestrutura mantida ou construídas até esses empreendimentos, e ao mesmo tempo, as terras próximas podem ser valorizadas.

Todavia, a realidade da RMGV, torna esse cenário ainda mais complexo devido uma significativa concentração fundiária nos municípios da região. No município de Serra, por exemplo, três proprietários de um número total de 234 , ou seja, $1,28 \%$, controlam aproximadamente $46,53 \%$ da área total dos estabelecimentos agropecuários do município. No município de Vila Velha $2,42 \%$ dos proprietários controlam uma área de 
aproximadamente $40,42 \%$ dos estabelecimentos agropecuários. Em Cariacica, 1,55\% dos proprietários controlam aproximadamente $28 \%$ dos estabelecimentos agropecuários. (ZANOTELLI et. al. 2014).

Mapa 1: Mancha urbana, perímetros urbanos e vazios periurbanos da RMGV.

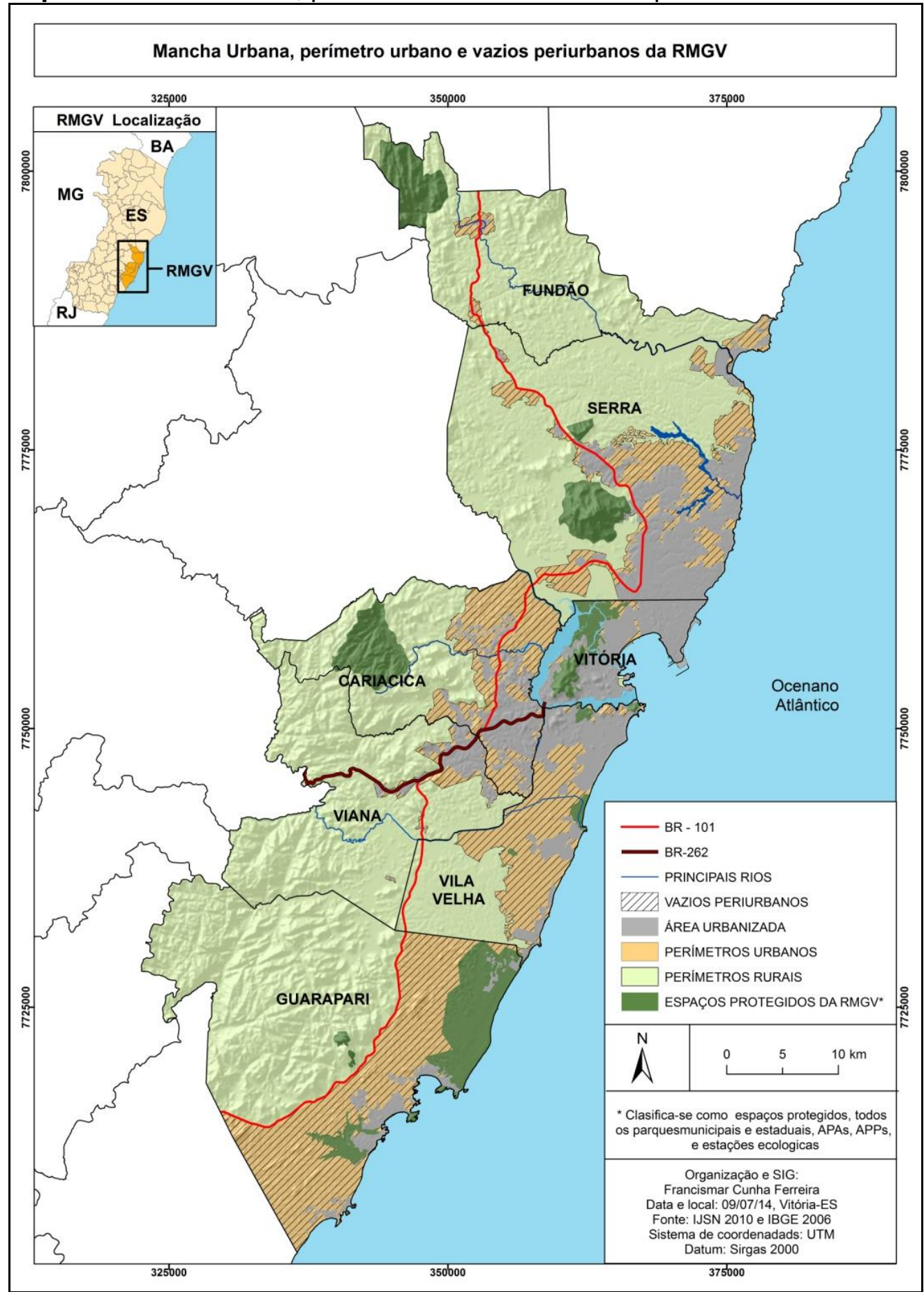

Fonte: Adaptado de Zanotelli et. al. 2014.

Nessa direção, destacam-se duas coisas. Uma primeira é que as municipalidades via definição de extensos perímetros urbanos, além de contribuir para a formação de vazios 
periurbanos, também possibilita com que os proprietários de fazendas que se localizam no entorno das áreas urbanas densas tenham suas terras valorizadas. Em outras palavras, as fazendas que passam a ter suas terras no interior da área urbana definida pelo perímetro urbano, possibilita com que seu proprietário possa vir a desenvolver as mais variadas e complexas estratégias de apropriação de uma renda da terra urbana. Esta última, de maneira geral, pode vir a ser superior a renda do setor agrícola, afinal, uma vez a fazenda localizada dentro da área urbana, ela guarda em seu interior a possibilidade do crescimento urbano futuro. Esse aspecto justifica, em parte, o porquê da terra urbana mesmo periférica e até mesmo sem infraestrutura urbana ser mais valorizada do que a terra rural (SILVA, 1995).

A segunda situação que se destaca, é que devido à concentração fundiária da RMGV, poucos proprietários de terras irão possuir um significativo poder de intervenção nos processos de expansão urbana. Esses proprietários podem vir a pressionar modificações dos zoneamentos, dos limites dos perímetros urbanos, dos índices urbanísticos e etc. em função, dentre outras coisas, da busca por uma maior renda da terra urbana.

Todavia, o problema de vazios urbanos não é verificado apenas em áreas periurbanas. Os vazios periurbanos são apenas uma modalidade dos vazios urbanos. Como apontado acima, no interior da mancha urbana consolidada existe uma grande quantidade de áreas/lotes vagos, esses que configuram a nossa segunda modalidade de vazios urbanos: os vazios urbanos dentro da mancha urbana, visíveis apenas em uma maior escala de análise. Analisamos os mesmo a seguir.

\section{A MORFOLOGIA DOS VAZIOS URBANOS DENTRO DA MANCHA URBANA DENSA}

Uma primeira referência sobre os vazios urbanos da RMGV que identificamos remete a um estudo realizado pelo IJSN (1994) com dados referentes a 1990. O referido estudo considerou em suas análises as áreas dos loteamentos implantados não ocupados como sendo os vazios existentes e também considerou a área dos loteamentos projetados (com projeto já aprovado e com certificado de anuência prévia) ainda não implantados como sendo os vazios projetados. Os dados deste estudo podem ser verificados no Quadro 2.

Não foi possível verificar o percentual desses vazios em relação à área urbana da região, pois não foi possível identificar a dimensão da área urbana dos municípios para o ano de 1990. Entretanto, esses valores podem indicar algumas tendências. Assim, analisando o quadro 2 nota-se que em 1990 a aglomeração de Vitória - desta feita contando tão somente com cinco municípios, aqueles que são relativamente conurbados, pois ainda não existia oficialmente a região metropolitana - tinha uma área de $81,126 \mathrm{~km}^{2}$ de lotes vagos existentes (formado por 146.475 lotes vagos) e $23,885 \mathrm{~km}^{2}$ de lotes projetados 
(formado por 43.123 lotes de loteamentos projetados e ainda não implementados) que somam ao todo uma área de $105,011 \mathrm{~km}^{2}$ de vazios urbanos composto por 189.598 lotes vagos. Isso representa uma área superior à área total do município de Vitória, o que indica a grande dimensão desses espaços (cf. quadro 1).

Quadro 2: Vazios urbanos no aglomerado urbano da Grande Vitória a partir dos loteamentos existentes e projetados - 1990

\begin{tabular}{|c|c|c|c|c|c|c|}
\hline Municípios & $\begin{array}{c}\text { Vazios } \\
\text { existentes } \\
\left.\mathbf{( k m}^{2}\right)\end{array}$ & $\begin{array}{c}\text { Vazios } \\
\text { projetados } \\
\left.\mathbf{( k m}^{2}\right)\end{array}$ & $\begin{array}{c}\text { Total de } \\
\text { vazios } \\
\text { existentes e } \\
\text { projetados } \\
\left.\mathbf{( k m}^{2}\right)\end{array}$ & $\begin{array}{c}\text { № de lotes } \\
\text { vagos } \\
\text { existentes }\end{array}$ & $\begin{array}{c}\text { № de lotes } \\
\text { vagos } \\
\text { projetados }\end{array}$ & $\begin{array}{c}\text { Total de } \\
\text { Lotes vagos } \\
\text { existentes e } \\
\text { projetados }\end{array}$ \\
\hline Cariacica & 15,852 & 2,227 & 18,08 & 28.621 & 4.020 & 32.641 \\
\hline Serra & 35,165 & 14,74 & 49,91 & 63.492 & 26.613 & 91.105 \\
\hline Viana & 8,27 & -- & 8,27 & 14.931 & -- & 14.931 \\
\hline Vila Velha & 17,552 & 6,35 & 23,9 & 31.691 & 11.465 & 43.156 \\
\hline Vitória & 4,287 & 0,568 & 4,86 & 7.740 & 1.025 & 8.765 \\
\hline Total & 81,126 & 23,885 & 105,011 & 146.475 & 43.123 & 189.598 \\
\hline
\end{tabular}

Fonte: IJSN, 1994.

Destaca-se ainda no quadro 2 que Serra era o município da Grande Vitória com a maior quantidade de áreas loteadas e lotes vagos existentes e projetados. Serra apresentou um total de $49,91 \mathrm{~km}^{2}$ de áreas vagas o que corresponde a $47,52 \%$ dos vazios identificados na Grande Vitória pelo IJSN (1994). O segundo município que apresentou a maior quantidade de áreas loteadas existentes e projetadas vazias foi Vila Velha com $23,9 \mathrm{~km}^{2}$ (constituído por 43.156 lotes vagos), o que representava $22,76 \%$ dos vazios urbanos da região em 1990. Em seguida aparece Cariacica com uma área total de $18,08 \mathrm{~km}^{2}$ (formado por 32.641lotes vagos) de lotes vazios existentes e projetados correspondendo a $17,22 \%$ dos vazios da região e Viana com $8,27 \mathrm{~km}^{2}$ (formado por 14.931 lotes vagos) de vazios urbanos representando $7,88 \%$ dos vazios urbanos de 1990 . Destaca-se que Viana era o único município que não apresentava loteamentos projetados. Finalmente, o município de Vitória apareceu com a menor quantidade de áreas vagas $4,86 \mathrm{~km}^{2}$ (formado por 8.765 lotes vagos) correspondendo a $4,63 \%$ dos vazios urbanos existentes e projetados da região em 1990 (IJSN, 1994).

$\mathrm{Na}$ busca de entender de modo mais detalhado e atual os vazios urbanos do interior da mancha urbana apontada como densa, realizamos a identificação dos vazios a partir de uma análise da fotografia aérea de 2008 em uma escala de 1:3000. Analisamos os vazios urbanos dentro da mancha urbana densa e os categorizamos conforme suas características: vazios com elevado potencial de edificação; áreas de interesse ambiental; vazios de uso coletivo; e por fim, vazios complexos. 
- Os vazios com elevado potencial de edificação são aqueles que têm condições favoráveis à edificação: lotes vagos (terrenos baldios), glebas vagas, grandes quintais remanescentes de pequenas edificações em grandes lotes, fazendas, etc.

- As áreas de interesse ambiental dentro da mancha urbana são áreas identificadas na fotografia aérea (ortofoto) que apresentam densa vegetação de porte médio ou alto, podendo ser resquícios de mata Atlântica, áreas brejosas, de mangues, restingas, lagoas e áreas de alagados. A classificação desta categoria se baseou nos zoneamentos apresentados pelos PDMs dos respectivos municípios da RMGV. Entretanto, a delimitação dos limites dessas áreas não ocorreu seguindo os limites estabelecidos nos PDMs, mas, seguiu as condições apresentadas pelo ambiente, baseado no padrão da vegetação, nas formas de ocupações das áreas, etc.

- Vazios de uso coletivo são representados aqui pelos campos de futebol identificado na mancha urbana. A opção por alocar essas áreas em uma categoria especial ocorreu em função de suas condições, podendo ser áreas públicas ou privadas que em um determinado momento são utilizadas coletivamente para o lazer, mas que mesmo em função disso, elas não perdem seu potencial construtivo.

- Vazios complexos são áreas que não são de interesse ambiental e nem de pleno uso coletivo, mas que se apresentam como espécies de "nós" para o planejamento, são espaços de lavra de pedreiras, aeroclubes, etc.

Após definida nossa classificação, realizamos o mapeamento identificando, localizando, classificando e medindo os vazios urbanos dentro da mancha urbana densa da RMGV. Os resultados podem ser verificados no Quadro 3 e no Mapa 2.

Analisando o quadro 3 e o mapa 2, o que se nota é que a grande quantidade de vazios urbanos dentro da mancha urbana densa se apresenta como sendo uma questão metropolitana, uma vez que as diferentes categorias de vazios urbanos se encontram em regiões centrais e periféricas.

Ao todo, foram identificadas por meio do mapeamento dos vazios urbanos dentro da mancha urbana densa aproximadamente $97,38 \mathrm{~km}^{2}$ de áreas vagas nos sete municípios da RMGV, o que representa aproximadamente $29,51 \%$ da área delimitada como sendo a mancha urbana densa $\left(330 \mathrm{~km}^{2}\right)$. Há de se notar que o primeiro tipo de vazio, com elevado potencial de edificação corresponde, de longe, à maior área dos vazios em área densa (24\% da mancha urbana). 
Quadro 03: Vazios urbanos dentro mancha urbana densa da RMGV identificados pela analise da ortofoto do IEMA de 2007/2008 seguindo os limites da mancha urbana de 2010

\begin{tabular}{|c|c|c|c|c|c|c|c|}
\hline \multicolumn{8}{|c|}{ (IJSN 2010). } \\
\hline Município & $\begin{array}{c}\text { (I) } \\
\text { Área da } \\
\text { mancha } \\
\text { urbana } \\
\text { consolidada } \\
\left(\mathrm{km}^{2}\right)\end{array}$ & $\begin{array}{c}\text { (II) } \\
\text { Vazios com } \\
\text { elevado } \\
\text { potencial de } \\
\text { edificação } \\
\left(\mathbf{k m}^{2}\right)\end{array}$ & $\begin{array}{c}\text { (III) } \\
\text { Áreas de } \\
\text { interesse } \\
\text { ambiental dentro } \\
\text { da mancha } \\
\text { urbana }\left(\mathrm{km}^{2}\right)\end{array}$ & $\begin{array}{c}(\text { IV }) \\
\text { Vazios de } \\
\text { uso } \\
\text { coletivo } \\
\left(\mathbf{k m}^{2}\right)\end{array}$ & $\begin{array}{c}(\mathrm{V}) \\
\text { Vazios } \\
\text { complexos } \\
\left(\mathrm{km}^{2}\right)\end{array}$ & $\begin{array}{c}(\mathrm{VI})=(\mathrm{II}+\mathrm{III}+\mathrm{IV} \\
+\mathrm{V}) \\
\text { Total de vazios } \\
\text { urbanos dentro da } \\
\text { mancha urbana } \\
\text { densa }\left(\mathrm{km}^{2}\right)\end{array}$ & $\begin{array}{l}\text { Percentual total } \\
\text { de área dos } \\
\text { vazios urbanos } \\
\text { dentro da mancha } \\
\text { urbana densa (\%) }\end{array}$ \\
\hline Cariacica & 64 & 12,93 & 0,55 & 0,39 & 0 & 13,87 & 21,67 \\
\hline Fundão & 5 & 1,51 & 0,05 & 0,018 & 0 & 1,578 & 31,56 \\
\hline Guarapari & 34 & 6,93 & 0,3 & 0,15 & 0,34 & 7,72 & 22,70 \\
\hline Serra & $\underline{100^{*}}$ & $\underline{31,98}$ & $12,8^{* *}$ & $\underline{0,63}$ & $\underline{0,49}$ & $\underline{45,9}$ & $\underline{45,9}$ \\
\hline Viana & 16 & $\overline{11,34}$ & 0 & $\overline{0,12}$ & 0 & $\overline{11,46}$ & 71,6 \\
\hline Vila Velha & 66 & 10,81 & 1,5 & 0,32 & 0,15 & 12,78 & 19,36 \\
\hline Vitória & 45 & 3,06 & 0,8 & 0,21 & 0 & 4,07 & 9,04 \\
\hline Total & 330 & 78,56 & 16 & 1,84 & 0,98 & 97,38 & 29,51 \\
\hline
\end{tabular}

${ }^{*}$ Inclui a APA de Praia Mole.

**As áreas não ocupadas da APA de Praia Mole fazem parte desta área.

Fonte: IJSN (2010) e IEMA (2008).

O município de Viana é o que proporcionalmente possui a maior porcentagem de vazios atingindo a marca de $71,6 \%$ de sua área urbana consolidada. Neste sentido, a urbanização de Viana além de dispersa evidência que sua mancha urbana é mais "vazia" do que ocupada. Serra também ganha destaque apresentando uma área de $45,9 \mathrm{~km}^{2}$, o que equivale a 45,9\% de sua área urbana densa, entretanto, deve-se salientar a grande quantidade de áreas de interesse ambiental atingindo $12,8 \mathrm{~km}^{2}$, mas que é muito inferior aos vazios gerais. A área dos vazios urbanos dentro da mancha urbana densa de Serra é maior do que a área urbana do município de Vitória e também do município de Guarapari (cf. quadro 1). É o município que apresenta a maior área de vazios urbanos dentro da mancha urbana densa ( $47 \%$ da mancha urbana da região).

Por sua vez, o município de Cariacica veio a apresentar uma área total de vazios urbanos no interior da mancha urbana densa de aproximadamente $13,87 \mathrm{~km}^{2}$, o que corresponde a $21,67 \%$ de sua mancha urbana densa. Vila Velha tem $12,78 \mathrm{~km}^{2}$ de vazios urbanos no interior da mancha urbana densa, o equivalente a $19,36 \%$ da mancha urbana densa do município. Por sua vez, Fundão tem $1,57 \mathrm{~km}^{2}$ de áreas vagas no interior de sua manha urbana. Uma área significativa, visto que a mancha urbana densa de Fundão é de 5 $\mathrm{km}^{2}$, portanto $31 \%$ de sua mancha urbana. Finalmente, Vitória tem uma área de $4,07 \mathrm{~km}^{2} \mathrm{de}$ vazios urbanos no interior da mancha urbana densa, o que corresponde a $9,04 \%$ da mancha urbana do município. 
Mapa 2: Vazios urbanos no interior da mancha urbana densa da RMGV em 2010.

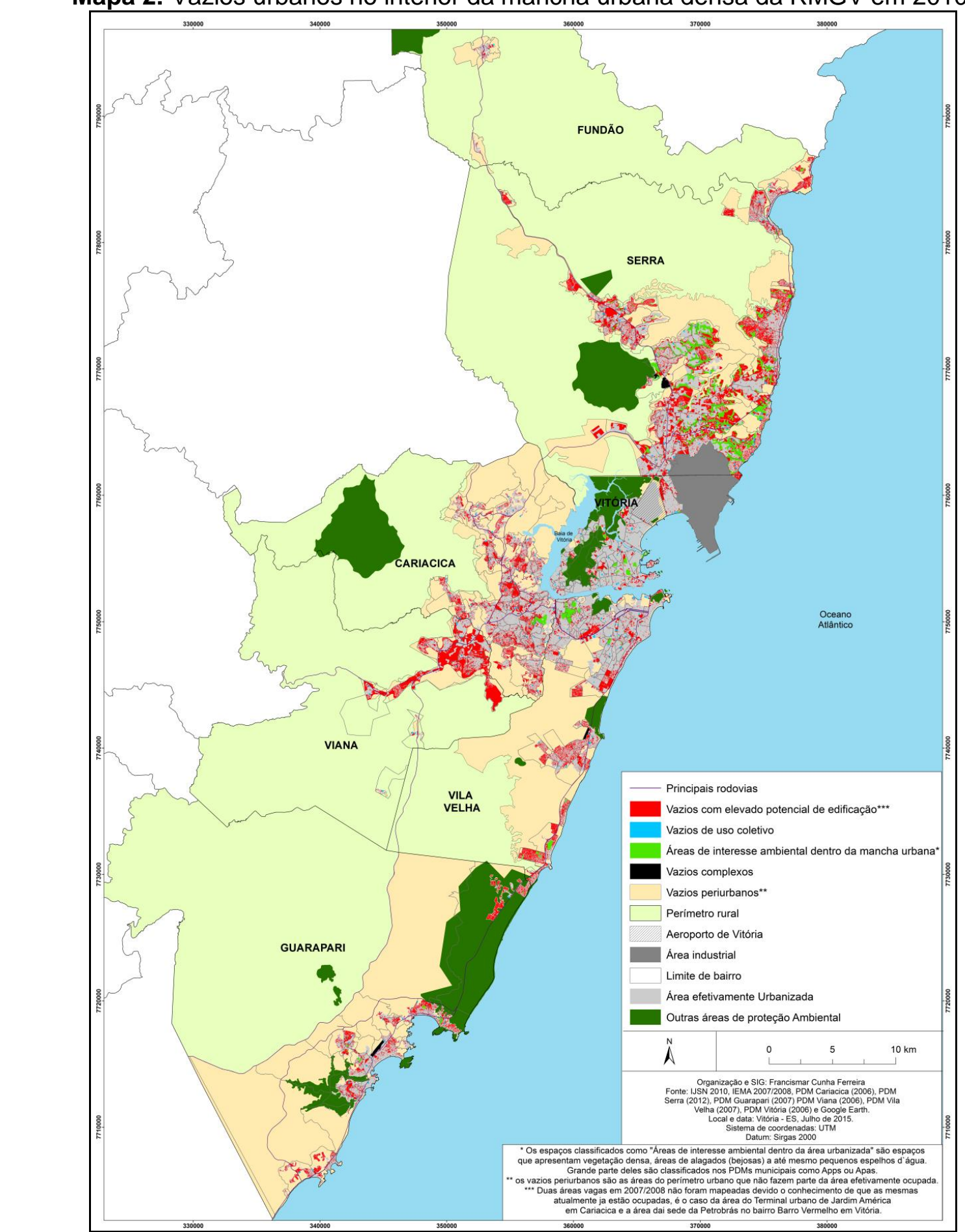

Fonte: Os autores.

Em relação às categorias de vazios urbanos, destaca-se que os vazios com elevado potencial de edificação correspondem a maior parte dos vazios urbanos no interior da mancha urbana densa. Ao todo, são $78,56 \mathrm{~km}^{2}$ desta categoria de vazio, o que corresponde a $80,67 \%$ da área total de vazios urbanos no interior da mancha urbana densa da RMGV. 
Destaca-se que desse total, grande parte $\left(31,98 \mathrm{~km}^{2}\right)$ se localiza em Serra, município que concentra parte importante de atividades industriais e imobiliárias da região.

A categoria vazios com elevado potencial de edificação pode ser equivalente, até certo ponto, pois não consideramos nela somente loteamentos, àquela classificação de lotes vagos existentes e projetados identificado pelo IJSN (1994) para o ano de 1990. Nesse sentido, podemos apontar que possivelmente entre 1990 e 2010 ocorreu uma diminuição da área total dos vazios urbanos no interior da mancha urbana densa da RMGV. Isso, pois, em nosso mapeamento referente ao ano de 2010 identificamos uma área de 78,56 km² de vazios com elevado potencial de edificação e o estudo do IJSN (1994) em 1990 havia na região $105,011 \mathrm{~km}^{2}$ de lotes vagos existentes e projetados. Além disso, o estudo do IJSN (1994) não levou, em consideração, ao contrário de nosso mapeamento, os municípios de Fundão e Guarapari. A área de vazios urbanos identificados pelo IJSN (1994) em 1990 para cinco municípios da região é superior à área total das diferentes categorias de vazios urbanos no interior da mancha urbana densa que foram identificadas em nosso mapeamento nos sete municípios da RMGV que foi de $97,38 \mathrm{~km}^{2}$ conforme apontado acima. Outro indicativo de uma possível redução desses espaços na região.

A categoria de vazio que apresenta a segundo maior área total na RMGV são as áreas de interesse ambiental dentro da mancha urbana. Ao todo, essa categoria de vazio possui uma área de $16 \mathrm{~km}^{2}$. A maior parte desta categoria de vazio se localiza no município de Serra, sendo uma área de $12,8 \mathrm{~km}^{2}$. No referido município, essa categoria de vazio, em grande parte, é representada por encostas e fundos de vales do relevo de tabuleiros costeiros. Entretanto, deve-se ressaltar que muitos dos vazios identificados como área de interesse ambiental, e também outras áreas de preservação da RMGV são controladas por proprietários de terras que buscam desenvolver diferentes estratégias de apropriação de renda da terra sobre as áreas, colocando em risco, assim, ambientes que deveriam ser preservado conforme demonstraram estudos de Zanotelli e Ferreira (2014) em relação às áreas de proteção ambiental de Vitória.

Quanto aos vazios de uso coletivo e os vazios complexos, eles correspondem aos vazios com menor expressão. Os vazios de uso coletivo possui uma área de 1,84 km², enquanto que os vazios complexos $0,98 \mathrm{~km}^{2}$.

Os vazios que se encontram no interior da mancha urbana densa, em especial aqueles que possuem elevado potencial de edificação, passaram e/ou estão passando por significativas transformações. Essas associadas, dentre outras coisas, à recente expansão da produção imobiliária para novas áreas da RMGV.

Somente entre 2005 e 2013 foram lançadas 68.681 unidades imobiliárias nos municípios de Vitória, Serra, Vila Velha e Cariacica (SINDUSON-ES, 2013 apud FERREIRA, 
2014). A dispersão da produção imobiliária recente da RMGV está dentre outras coisas, associadas à busca por terras relativamente baratas para a construção e também à criação do Programa Minha Casa Minha Vida (PMCMV) em 20096. Um programa destinado à construção de moradias para a população que possui rendimento de até 10 salários mínimos e que foi elaborado em parceria entre Governo Federal e empresas da construção civil financerizadas (MARICATO, 2011). Essa dispersão da produção imobiliária levou consigo uma valorização imobiliária na RMGV. Consequentemente, os proprietários dos vazios urbanos, em especial daqueles com elevado potencial de edificação (mas também de outros vazios como os de uso coletivo, onde em Viana, por exemplo, um campo de futebol deu lugar a um empreendimento do PMCMV), em função do monopólio que praticam sobre determinadas frações de terra do espaço urbano, buscam captar parte desta valorização imobiliária via reivindicação de uma maior renda da terra. Tal fato implica num processo ainda mais intenso de segregação urbana motivada pela elevação do preço da terra e de imóveis.

Entretanto, para conhecermos a área total dos vazios urbanos da RMGV, se faz necessário realizar a soma dos vazios periurbanos e dos vazios urbanos dentro da mancha urbana densa. No Quadro 04 pode ser analisada esta soma por município da RMGV.

Quadro 4: Área total dos vazios urbanos da RMGV.

\begin{tabular}{|c|c|c|c|c|c|c|c|}
\hline Município & $\begin{array}{l}\text { Área total } \\
\text { dos vazios } \\
\text { periurbano } \\
\mathbf{s}\left(\mathbf{k m}^{2}\right)\end{array}$ & $\begin{array}{c}\% \text { de área } \\
\text { dos vazios } \\
\text { periurbano } \\
\text { s (\%) }\end{array}$ & $\begin{array}{c}\text { Área total } \\
\text { dos vazios } \\
\text { urbanos em } \\
\text { áreas } \\
\text { densas } \\
\left(\mathrm{km}^{2}\right)\end{array}$ & $\begin{array}{l}\text { \% de área dos } \\
\text { vazios urbanos } \\
\text { em áreas densas } \\
\text { em relação a } \\
\text { mancha urbana } \\
\text { consolidada }\end{array}$ & $\begin{array}{c}\text { \% de área dos } \\
\text { vazios urbanos } \\
\text { em áreas } \\
\text { densas em } \\
\text { relação ao } \\
\text { perímetro } \\
\text { urbano }\end{array}$ & $\begin{array}{l}\text { Área total } \\
\text { dos } \\
\text { vazios } \\
\text { urbanos } \\
\text { da RMGV } \\
\left(\mathbf{k m}^{2}\right)^{\star}\end{array}$ & $\begin{array}{l}\text { Percentual } \\
\text { de área } \\
\text { total dos } \\
\text { vazios da } \\
\text { RMGV }(\%)^{\star \star}\end{array}$ \\
\hline Cariacica & 65,31 & 50,51 & 13,87 & 21,67 & 10,73 & 79,18 & 61,23 \\
\hline Fundão & 12,21 & 70,95 & 1,578 & 31,56 & 9,17 & 13,788 & 80,12 \\
\hline Guarapari & 223,78 & 86,81 & 7,72 & 22,71 & 2,99 & 231,5 & 89,81 \\
\hline Serra & 91,55 & 47,79 & 45,9 & 45,90 & 23,96 & 137,45 & 71,76 \\
\hline Viana & 12,6 & 44,06 & 11,46 & 71,63 & 40,07 & 24,06 & 84,13 \\
\hline Vila Velha & 69,67 & 51,35 & 12,78 & 19,36 & 9,42 & 82,45 & 60,77 \\
\hline Vitória & 29,4 & 34,06 & 4,07 & 9,04 & 4,71 & 33,47 & 38,77 \\
\hline Total & 504,52 & 59,60 & 97,38 & 29,51 & 11,50 & 601,90 & 71,11 \\
\hline
\end{tabular}

${ }^{*}$ Representa a soma dos vazios periurbanos e dos vazios urbanos em áreas densas.

** Representa o percentual dos vazios periurbanos e dos vazios urbanos em áreas densas em relação a área "dita" urbana delimitada pelo perímetro urbano.

Fonte: Zanotelli et. al. (2014), Ferreira (2015), IEMA (2007/2008) e IJSN (2010).

Estudando o quadro 04, nota-se que o espaço pretensamente urbano da RMGV toda área delimitada pelos perímetros urbanos dos municípios - é mais "vazio" do que ocupado, pois $71,11 \%\left(601,9 \mathrm{~km}^{2}\right)$ da área da região correspondem aos vazios urbanos (vazios periurbanos mais vazios urbanos dentro da mancha urbana densa). O município de 
Guarapari proporcionalmente se destaca com a maior área vaga atingindo $89,81 \%$ de sua área definida como urbana pelo perímetro urbano, seguido de Viana com 84,13 \%, Fundão com $80,12 \%$, Serra com 71,76\%, Cariacica com $61,23 \%$, Vila Velha com $60,77 \%$ e finalmente a capital Vitória com $38,77 \%$ como sendo o único município onde o percentual de área ocupada é superior ao percentual de áreas vagas ${ }^{7}$.

Em geral, os vazios urbanos, não podem ser pensados apenas como espaços residuais do processo de urbanização. Esses espaços, em especial aqueles que apresentam elevado potencial de edificação e também os vazios periurbanos, são resultados do controle da terra sob a forma de propriedade privada como reserva de valor que determina seus usos (nas áreas periféricas ou semi-periféricas) ou os usos demandados de maneira crescente nas áreas centrais determinam os preços crescentes nesses lugares. São espaços utilizados, em grande parte, como forma de captação de parte da mais valia global sob a forma de renda (renda fundiária e/ou imobiliária) por parte de seus proprietários e que estão diretamente articuladas às lógicas de produção do espaço urbano capitalista. Neste sentido, as dimensões e localizações dos vazios urbanos nos apontam como que a busca pela renda da terra por parte de proprietários de terra pode ter uma significativa intervenção na produção e organização do espaço urbano, contribuindo para a expansão dispersa urbana, custosa para as municipalidades, e ao mesmo tempo segregadora.

\section{CONSIDERAÇÕES FINAIS}

A pesquisa buscou localizar, medir e categorizar os vazios urbanos RMGV. Notou-se que os vazios se apresentam em regiões centrais e periféricas, e, que grande parte dos vazios da região surge devido à definição exagerada de perímetros urbanos em relação à mancha urbana "densa". Esse processo, num primeiro momento promove a valorização das terras que se apresentam como vazios periurbanos, isso, pois, uma vez a terra vindo a ser classificada como passível de ser urbanizada, ela possibilita com que seu proprietário busque se apropriar de uma renda da terra urbana, que de modo geral, é superior a renda do setor agrícola. Além disso, destaca-se à significativa concentração fundiária da região, que faz com que poucos tenham um grande poder de intervenção nos processos de expansão urbana em função da renda da terra urbana almejada por esses proprietários. Em geral, foi constatado que $59,6 \%$ do espaço urbano delimitado pelos perímetros urbanos da RMGV é composto de "vazios periurbanos".

Notou-se também que no interior da mancha urbana densa da RMGV se verifica uma significativa presença de vazios urbanos: $29,51 \%$ da mancha urbana apontada como densa da RMGV é "vazia" (11,5\% do perímetro urbano). Destaca-se que grande parte desses 
vazios são aqueles que apresentam elevado potencial de edificação e que se encontram em maior parte no município de Serra.

Em síntese foi percebido que a área urbana da RMGV é mais "vazia" do que edificada. $71,11 \%$ da área urbana da RMGV delimitada pelos perímetros urbanos dos municípios se apresenta como vazios urbanos. Essas terras tem a propriedade concentrada (Zanotelli et. al, 2014) o que nos permite pensar que interesses rentistas sobre os vazios urbanos em geral, possuem poder de intervenção sobre a expansão urbana da região via a delimitação de perímetros urbanos exagerados (com pressões as mais diversas realizadas sobre as prefeituras quando da delimitação desses perímetros) e a manutenção de muitas propriedades de terras vazias dentro da mancha urbana relativamente densa.

\section{REFERÊNCIAS}

BORDE, A. Vazios urbanos: avaliação histórica e perspectivas contemporâneas. Revista Brasileira de Estudos Urbanos e Regionais. Rio de Janeiro - RJ, vol. 8 n. 5, 2004.

CAMPOS, M. M. Vazios operativos da cidade. Territórios interurbanos na Grande Vitória (ES). Tese de doutorado, PUC-SP, 2004.

FERREIRA, F. C. Propriedade fundiária, os "vazios urbanos" e a organização do espaço urbano: o caso de Serra na Região Metropolitana da Grande Vitória - ES (RMGVES). Dissertação Mestrado. Mestrado em Geografia - UFES, 2015.

HARVEY, D. A Justiça Social e a Cidade. São Paulo: Hucitec, 1980.

HARVEY, D. Os limites do Capital. São Paulo. Boitempo. 2013.

IBGE: Censo Demográfico 2010. 2010.

IEMA: Ortofotos - ES. 2007/2008.

IJSN: Grande Vitória em dados. Vitória, 1994.

IJSN: Mancha Urbana RMGV 2010: formato shapefile. 2010.

MARICATO, E. O impasse da política urbana no Brasil. São Paulo: Editora Vozes, 2011.

SILVA, H. M. M. B. Vazios urbanos: requalificando o problema na Grande São Paulo. In: Seminário Internacional sobre vazios urbanos. Rio de Janeiro, 1999.

SILVA, J. M. Valorização Fundiária e expansão urbana recente em Guarapuava - PR. Dissertação (Mestrado em Geografia) - Centro de Filosofia e Ciências Humanas, Universidade Federal de Santa Catarina, Florianópolis. 1995.

SPERANDELLI, D. L. Dinâmica e análise do crescimento, dos vazios e das áreas verdes urbanas de Atibaia, SP. Dissertação de Mestrado. Programa de pós-graduação em Meio Ambiente e Recursos hídricos. Universidade Federal de Itajubá. Itajubá-MG, 2010.

TARDIN, R. Espaços livres: sistema e projeto territorial. Rio de Janeiro, RJ: 7 Letras, 2008.

TEIXEIRA, T. FURTADO, F. Reinserção de Vazios Urbanos: diretrizes para a política urbana municipal, a partir do caso de Juiz de Fora /MG. ANPARQ - Arquitetura, cidade, paisagem e território: percursos e prospectivas. Rio de Janeiro, 2010.

ZANOTELLI, C. L. et. al. A renda da terra na Região Metropolitana da Grande Vitória - ES Brasil. Confins, v. 21, 2014. 
ZANOTELLI, C. L.; FERREIRA, F. C. O espaço urbano e a renda da terra. Geotextos, v. 10, p. 35-58, 2014.

\footnotetext{
${ }^{1}$ Mestre em Geografia pela Universidade Federal do Espírito Santo - UFES,

E-mail: francismar.cunha@gmail.com

${ }^{2}$ Doutor em Geografia Humana Econômica e Regional - Paris X - Nanterre, Professor no Programa de Pós-Graduação em Geografia da UFES, E-mail: clzanotelli@yahoo.com.br
}

${ }^{3}$ Para um debate mais aprofundado sobre a renda da terra na perspectiva marxista ver Marx (1988) Harvey (1980, e 2013). Sobre um debate relativo à renda da terra e o espaço urbano na região de Vitória ver Zanotelli e Ferreira (2014), Zanotelli et. al. (2014), Ferreira (2015).

${ }^{4} \mathrm{O}$ formato shapefille ou shape constitui um tipo de arquivo digital que representa um conjunto de elementos gráficos de dados referentes aos fenômenos espaciais que contém uma referência espacial baseada no sistema de coordenadas geográficas.

${ }^{5}$ Alguns autores também incluem no conceito de vazios urbanos domicílios vagos, construções abandonadas e etc. (BORBE, 2004).

${ }^{6}$ Além da busca por terra para a construção e a criação do PMCMV, Ferreira (2014) aponta que a expansão da produção imobiliária na RMGV para novas áreas também está associada à chegada de empresas da construção capitalizadas em bolsas de valores externas ao Espírito Santo (Cyrela, MRV, Rossi e etc.) e também da conjuntura da produção imobiliária em escala nacional representados por marcos regulatórios que deram maior segurança para incorporadores, construtores e investidores, pelo aumento de recursos provenientes do Sistema Brasileiro de Poupança em Empréstimo (SBPE) e do Fundo de Garantia do Tempo de Serviço (FGTS) e ainda, a melhoria do crédito para pessoa física a partir da diminuição das taxas de juros, da ampliação dos prazos de pagamento e da redução do valor das parcelas de entrada.

${ }^{7}$ A situação dos espaços vazios da Grande Vitória ainda se torna mais agravante quando se leva em conta a dimensão dos vazios urbanos e o número de domicílios vagos na grande Vitória. Conforme os estudos de Zanotelli et.al. (2014) a RMGV apresentou 66.306 domicílios vagos em 2010 e mais 30 mil em construção em 2012 (ZANOTELLI et. al. 2014). 